\title{
Letters
}

Website: www.bmj.com

Email: letters@bmj.com

\section{Sunlight and health}

\section{Use of sunscreens does not risk vitamin} D deficiency

EDITOR-Ness et al misinterpret our work in Australia by stating that we showed that use of sunscreens reduced vitamin D concentrations. ${ }^{1}$ In fact, we showed that the use of sunscreens did not prevent the normal summer rise in 25-hydroxy vitamin $\mathrm{D}$ concentration (the vitamin D fraction that is used to assess vitamin D deficiency). ${ }^{2}$ Subjects using sunscreens compared with controls using a placebo cream had an equal rise over the summer.

As an extension of the study we also measured concentrations of 1,25-hydroxy vitamin $\mathrm{D}$. This fraction of vitamin $\mathrm{D}$ is believed to be regulated by 25-hydroxy vitamin $\mathrm{D}$ concentrations via a negative feedback mechanism. We found a rise in 1,25-hydroxy vitamin D concentrations over the summer in people using sunscreen, but the rise was smaller than that among those using placebo. In a small group there was a lower, but not significantly different, concentration of 1,25-hydroxy vitamin $\mathrm{D}$ at the end of summer. However, this occurred in the presence of a substantial rise in 25-hydroxy vitamin $\mathrm{D}$ concentrations (the vitamin D

\section{Advice to authors}

We prefer to receive all responses electronically, sent either directly to our website or to the editorial office as email or on a disk. Processing your letter will be delayed unless it arrives in an electronic form.

We are now posting all direct submissions to our website within 24 hours of receipt and our intention is to post all other electronic submissions there as well. All responses will be eligible for publication in the paper journal.

Responses should be under 400 words and relate to articles published in the preceding month. They should include $\leqslant 5$ references, in the Vancouver style, including one to the BMJ article to which they relate. We welcome illustrations.

Please supply each author's current appointment and full address, and a phone or fax number or email address for the corresponding author. We ask authors to declare any competing interest. Please send a stamped addressed envelope if you would like to know whether your letter has been accepted or rejected.

Letters will be edited and may be shortened.

www.bmj.com

letters@bmj.com fraction that controls 1,25-hydroxy vitamin D) in all subjects. We also made it clear in our paper that the 1,25-hydroxy vitamin $\mathrm{D}$ concentrations of all the participants in the placebo and sunscreen groups remained within the normal range all the way through the study.

It is mischievous and specious to imply that our work was suggesting that use of sunscreen might lead to vitamin D deficiency. We made the opposite point very strongly in the paper and clearly explained why, in the presence of raised 25-hydroxy vitamin D concentrations, the slightly smaller changes in 1,25-hydroxy vitamin D could not be interpreted as a risk for vitamin $\mathrm{D}$ deficiency.

Robin Marks professor of dermatology St Vincents Hospital, Melbourne, Fitzroy Victoria 3065, Australia

ebejerjd@svhm.org.au

1 Ness AR, Frankel SJ, Gunnell DJ, Smith DG. Are we really dying for a tan? $B M J$ 1999;319:1 14-6. (10 July.)

2 Marks R, Foley PA, Jolley D, Knight, KR, Harrison J, Thompson SC. The effect of regular sunscreen use on vitamin D levels in an Australian population. Arch Dermatol 1995;131:415-21.

\section{Article did not help informed debate}

EDIToR-Debating the content of health education messages, the scientific evidence on which they are based, and their likely effects, both bad and good, is important provided that the debate is constructive and based on a sound literature review. Unfortunately the article by Ness et al inadequately addresses the debate about sun protection.

The article opens with the statement that certain professionals embrace the notion that "sunlight is bad for health," implying that the message has been to avoid sun exposure. This misrepresents the advice given, which includes "avoiding excessive sun exposure" and "encouraging gradual sun exposure."'

No short article can do justice to the extensive research, both epidemiological and experimental, into the role of exposure to ultraviolet radiation in the aetiology of skin cancer. The limitations and uncertainties about our understanding of the problem have been the subject of international, interdisciplinary debate. The dilemma facing those who wish to prevent extensive morbidity from skin cancer, and rising mortality from melanoma, is that effective primary prevention may take 20 years or more to reduce the incidence of disease. As is the case with the prevention of other diseases, there has been much pressure to promote lifestyle and dietary changes.

Ness et al suggest that early detection and treatment may be more beneficial than primary prevention in reducing mortality from melanoma, but in countries with a low incidence of melanoma we have yet to agree on a cost effective strategy for early detection. ${ }^{3}{ }^{4}$ Nor do the authors address the psychological and financial costs of diagnosis and treatment.

Primary prevention undoubtedly brings costs as well as benefits. However, there is insufficient evidence at this stage for Ness et al to suggest that recommendations on sun exposure should be promoted to prevent one disease at the expense of another. It may well be that greater understanding of the problem will enable development of recommendations on sun exposure that can benefit more than one condition.

It is essential that people should have the opportunity to make fully informed choices about their lifestyles and that decisions on prevention are based on the best available evidence. Although Ness et al raise important questions about how best to prevent skin cancer, from an epidemiological view the article is disappointing because it has not adequately reviewed all the health issues and because it has misrepresented at least two studies. ${ }^{25}$

Jane Melia epidemiologist

Cancer Screening Evaluation Unit, Institute of Cancer Research, Sutton, Surrey SM2 5NG melia@icr.ac.uk

1 Ness AR, Frankel SJ, Gunnell DJ, Davey Smith G. Are we really dying for a tan? $B M J$ 1999;319:114-6. (10 July)

3 Sinclair R. Commentary: Start with the KISS principle. BMJ 1998:316:38-39.

4 Melia J. Changing incidence and mortality from cutaneous malignant melanoma: the reasons are not yet clear. BMJ 1997;315:1106-7.

5 Marks R, Foley PA, Jolley D, Knight KR, Harrison J, Thompson SC. The effect of regular sunscreen use on vitamin D levels in an Australian population. Arch Dermatol $1995 ; 131: 415-21$

\section{Not all sunlight is dangerous, just} ultraviolet radiation

EDITOR-By referring to just sunlight rather than its individual components, Ness et al apparently fail to understand the message which photobiologists and dermatologists have been seeking to put to the public for many years. ${ }^{1}$ Sunlight, as the authors imply, is indeed essential to life, but its warmth and light are all we need. The third component, ultraviolet radiation, is universally harmful to the skin, although usually not noticeably so in the early years of life. 
Now that we live much longer, however, exposure to ultraviolet radiation has become of major importance. It causes photoageing of skin in virtually everyone, particularly the fair skinned, inducing a dry, often itchy, wrinkled, blotchy, telangiectatic effect, ${ }^{2}$ and skin cancer in a significant but steadily increasing minority. About 50000 people in the United Kingdom develop skin cancer each year, nearly 2000 of whom die; however, the number of cases is beginning to fall in countries, such as Australia, where community ultraviolet avoidance programmes are well established. ${ }^{3}$ The authors assert that these death rates are not very high and that only a small reduction will be achieved by avoiding sunlight. Nevertheless, any skin cancer is detrimental to the sufferer and costly to health services, particularly when preventive measures are readily available. The high outlay on cosmetics and surgery to repair photoageing could also be significantly reduced.

Ness et al further state that mental health, and particularly seasonal affective disorder, is improved by sunlight. But this effect is by exposure to the essentially harmless visible light spectrum through the eye, not to damaging ultraviolet radiation through the skin. ${ }^{4}$ Similarly, vitamin D is readily available in a normal diet, and not sunbathing is unlikely to lead to a deficiency. ${ }^{5}$

What we must understand is that ultraviolet radiation is the sunlight we must avoid and that this is at its most intense between about 11 am and $3 \mathrm{pm}$ in Britain in summer and all year round in tropical climates, even on cloudy or cool days. Adequate protection at such times can easily be achieved by covering up with appropriate clothing, seeking the shade when possible, and using a high protection sunscreen on exposed skin. At other times, however, even in hot and sunny conditions, the ultraviolet intensity is much weaker and less caution is needed; if sunscreens are used the risk is further minimised.

J L M Hawk professor of dermatological photobiology Department of Photobioology, St Thomas's Hospital, London SE1 7EH

1 Ness AR, Frankel SJ, Gunnell DJ, Davey Smith G. Are we really dying for a tan? $B M J$ 1999;319:114-6. (10 July.)

2 Herschenfield RE, Gilcrest RA. The cumulative effects of ultraviolet radiation on the skin. In: Hawk JLM, ed Photodermatology. London: Arnold, 1999:69-87.

3 Staples M, Marks R, Giles G. Trends in the incidence of Staples M, Marks R, Giles G. Trends in the incidence of non-melanocytic skin cancer (NMSC) treated in Australi 1985-1995; are primary prevention programs starting to

4 Partonen T, Lonnqvist J Seasonal affective disorder. Lancet 1998:352:1369-74.

5 Marks R, Foley PA, Jolley D, Knight KR, Harrison J, Thompson SC. The effect of regular sunscreen use on vitamin D levels in an Australian population. Arch Dermato 1996;131:415-21.

\section{Severity of effect depends on where you} live

Editor-Ness et al questioned the advice given by public health authorities to reduce exposure to sunlight. ${ }^{1}$ Without quantifying the risks and benefits of sun exposure across the population, the authors reasoned, isn't it unethical to advocate a change in behaviour? They then conducted a brief review of known harms and possible benefits of sunlight exposure and concluded that increased exposure to the sun might be beneficial when assessed on a population basis. Predictably, the article has created a storm in the lay press, but what of its scientific content?

The question posed is certainly reasonable. However, the article is flawed by superficial interpretation, a disturbing tendency to equate conjecture with evidence, and a failure to appreciate the adverse effects of sun exposure experienced by people living in other parts of the world. For example, the authors claim that reductions in mortality from melanoma by reducing exposure to the sun will be small and suggest that it would be better to train the public to consult doctors at an earlier stage in the disease process. Even in countries with low rates of melanoma, such as England and Wales, these claims are contentious; when applied to the sun ravaged populations of Australia, New Zealand, and low latitude United States, they are incomprehensible.

Two possible benefits of sunlight exposure were expounded: a reduction in coronary heart disease and improvements in mood and wellbeing, although the evidence proffered for these claims was extremely weak. Assuming that high levels of sunlight exposure are beneficial, then at the crudest level fair skinned Australians might be predicted to have lower cardiovascular mortality and fewer suicides than their northern European cousins. However, death rates for heart disease among Australian men in the MONICA cohorts are higher than those for Iceland, Denmark, or Sweden, ${ }^{2}$ and suicide rates in Australia are among the highest in the world. ${ }^{3}$ Moreover, people who migrate from England, Wales, and Ireland to Australia commit suicide at higher rates than those who remain behind.

Most people would agree that simple health education messages are blunt tools for addressing complex health problems, but I wonder about the consequences of the high profile strategy adopted by Ness et al. The distilled message of the article (intended or otherwise) that "sunlight is good for you" will echo far beyond the lush pastures of the Avon valley into dusty, sunburnt townships half a world away. It is here that the damage will be done.

David C Whiteman Nuffield medical research fellow Imperial Cancer Research Fund General Practice Research Group, Institute of Health Sciences, University of Oxford, Oxford OX3 7LF david.whiteman@dphpc.ox.ac.uk 1 Ness AR, Frankel SJ, Gunnell DJ, Davey Smith G. Are we
really dying for a tan? BMJ 1999;319:114-6. (10 July.)
2 Tunstall-Pedoe H, Kuulasmaa K, Amouyel P, Arveiler D,
Rajakangas AM, Pajak A. Myocardial infarction and coron-
ary deaths in the World Health Organization MONICA

Increases in incidence of breast and colonic cancer associated with $10 \%$ decrease in sunlight at mean exposure

\begin{tabular}{lllc} 
Study & Site & Country & Increase in incidence (\%) \\
\hline Garland and Garland, $1980^{2}$ & Colon & United States & 12 \\
\hline Garland et al, $1990^{3}$ & Breast & United States & 6 \\
\hline Gorham et al, $1990^{4}$ & Breast & Russia & 10 \\
\hline Emerson and Weiss, $1992^{5}$ & Colon & United States & 7 \\
\hline
\end{tabular}

project. Registration procedures, event rates, and casecontinents. Circulation 1994;90:583-612.

3 La-Vecchia C, Lucchini F, Levi F. Worldwide trends in suicide mortality, 1955-1989. Acta Psychiatr Scand 1994;90: 53-64. try of birth. Psychol Med 1998;28:201-8.

\section{Exposure to sunlight may reduce cancer} risk

EDITOR-The criticism of Ness et al's article questioning the acceptance of sunlight as being bad for health ${ }^{1}$ in the lay press underlines how the authors have dared to question one of the axiomatic tenets of modern preventive medicine. Sunlight exposure is viewed as one of the major avoidable causes of cancer, ranking alongside cigarette smoking in the demonology of medicine. It is therefore surprising that the authors did not consider the evidence that, far from causing cancer, sunlight exposure might actually be a potent agent for its prevention.

Several studies have examined the relation between sunlight exposure and internal malignancy. Several of these give sufficient information to allow the effect of changing sunlight exposure on the expected rate of malignancy to be estimated. All the studies show a negative relation of similar magnitude (table), particularly for breast and colon cancer.

In 1995 there were about 30000 new cases each of breast and large bowel cancer in the United Kingdom and about 30000 deaths from the two tumours combined. The most conservative of the estimates from the above studies suggest that a $10 \%$ decrease in sunlight exposure might lead to a $6 \%$ increase in these figures. This would approximate to 1800 extra cases of each of the tumours and 1800 extra cancer deaths. This figure exceeds the total number of deaths due to malignant melanoma, which are unlikely to be totally prevented by such a modest reduction in sunlight exposure.

Thus, reducing exposure to solar radiation, far from preventing cancer, may have the opposite effect. Further research is urgently needed to determine whether this is the case. If the increase is confirmed it will be necessary to determine what aspect of sunlight protects against cancer. Vitamin D or its metabolites may play an important part, offering hope for a strategy of moderating sunlight exposure to minimise the risk of skin cancer but replacing vitamin $\mathrm{D}$ to prevent internal malignancy.

Peter L Selby lecturer in medicine

Peter.Selby@man.ac.uk

E Barbara Mawer professor

Department of Medicine, Manchester Royal Infirmary, Manchester M13 9WL fatality rates in 38 populations from 21 countries in four

4 Burvill PW. Migrant suicide rates in Australia and in coun- 
1 Ness AR, Frankel SJ, Gunnell DJ, Davey Smith G. Are we really dying for a tan? BMJ 1999;319:114-6. (10 July.)

2 Garland CF, Garland FC. Do sunlight and vitamin D reduce the likelihood of colon cancer? Int J Epidemiol 1980;9:227-231

3 Garland FC, Garland CF, Gorham ED, Young JF. Geographic variation in breast cancer mortality in the United States: A hypothesis involving exposure to solar radiation. Prev Med 1990;19:614-22

4 Gorham ED, Garland FC, Garland CF. Sunlight and breast cancer incidence in the USSR. Int I Epidemiol 1990;19:820-824

5 Emerson JC, Weiss NS. Colorectal cancer and solar radiation. Cancer Causes and Control 1992;3:95-9.

\section{Authors' reply}

EDITOR-Exposure to sunlight clearly is not unequivocally noxious, as has been observed by others. ${ }^{12}$ Our article was an attempt to consider harm in the context of some potentially protective effects and to suggest that health education messages may be less fragile if a more balanced portrayal of risk and benefit is offered to the public than is sometimes the case. The intemperate tone of some of the responses to our article shows how some issues can become more sectarian than scientific.

Turning to the substantive points raised, Marks and Melia suggest that we have misrepresented the results of a randomised controlled trial of sunscreens. ${ }^{3}$ In this study 113 adults living in Victoria, Australia, were randomised to either sunscreen or placebo over the course of an Australian summer. Concentrations of 25-hydroxy vitamin D and 1,25-hydroxy vitamin $\mathrm{D}$ were measured at the beginning and end of the study. The rise in 25-hydroxy vitamin $\mathrm{D}$ concentrations was similar in both groups, but the rise in 1,25-hydroxy vitamin $\mathrm{D}$ was lower in those allocated to receive sunscreen: a $1.5 \%$ increase from baseline versus a $13.3 \%$ increase $(P=0.009)$. To call this "a slightly smaller change," as Marks does, is surely misleading. This study population was exposed to much stronger sunlight than that in temperate climates; furthermore, the sample studied probably experienced a higher than average sun exposure for Australians as they had a history of solar keratoses. Despite these characteristics the study provides evidence that sunscreens may affect vitamin D values. An extreme example of the danger of extrapolating from the Australian experience to less sunny climates is provided by the recent report of a case of rickets in a white child in Toronto who had been covered in sunscreen. ${ }^{4}$

Whiteman points out that we focused on a British population. Clearly, the balance of risks and benefits will differ between climates and populations, and the appropriate public health message will vary. Whiteman also suggests that because exposure to sunlight does not explain several population differences in disease risk it cannot be important This observation ignores the multifactorial nature of the aetiology of melanoma, and many examples-such as the high male smoking rate and very low coronary heart disease rate in Japan-show the misplaced reassurance that can follow from such comparisons. Selby and Mawer draw our attention to the evidence that exposure to sunlight may in fact reduce risk of some cancers. Although this evidence is tentative, it supports our contention that more sophisticated risk-benefit analyses are required in the formulation of public health policy.

Andrew R Ness senior lecturer in epidemiology Stephen J Frankel professor of epidemiology and public health medicine

David J Gunnell senior lecturer in epidemiolog George Davey Smith professor of clinical epidemiology

Department of Social Medicine, University of Bristol, Bristol BS8 2PR

1 Diffey BL. Sun protection: have we gone too far? $\mathrm{Br} J$ Derm 1998;138:544-64.

2 Report of the Subgroup on Bone Health, Working Group on the Nutritional Status of the Population of the Committee on Medical Aspects of Food and Nutrition Policy. Nutrition and bone health. London: Stationery Office, 1998:3. (Recommendation 18.)

3 Marks R, Foley PA, Jolley D, Knight KR, Harrison J, Thompson SC. The effect of regular sunscreen use on vitamin D levels in an Australian population. Arch Derm 1995;131:415-21.

Zlotkin S. Vitamin D concentrations in Asian children living in England. BMJ 1999;318:1417. (22 May.)

\section{Intervention trial for late life depression defended}

Editor-We would like to respond to several criticisms of our study ${ }^{1}$ raised in Haynes's editorial ${ }^{2}$ and in Deeks and Juszczak's commentary.

Haynes argues that our study is limited by patients refusing to participate or dropping out. In the context of studies in elderly people, we think that our refusal and follow up rates were reasonable. It is difficult to recruit elderly people into research studies $^{4}$ and maintain their participation. Considerable drop out rates were expected because our sample consisted of frail older people, many of whom died or became too ill to participate.

Haynes considers that our difficulty in recruiting and retaining doctors and patients compromised our community based intervention. Although maximising participation is important, the practical difficulties of fully engaging a community of busy doctors and frail elderly people needs acknowledgment. The educational programme was attended by the general practitioners of $62 \%$ of the participants in the intervention group and by 35 of the 71 (49\%) general practitioners caring for the 1036 residents interviewed. These attendance rates are above average for continuing medical education in general practice Although 28\% of participants in the intervention group attended exercise classes, remember that we sought to reach old, frail, depressed people unlikely to exercise. Furthermore, by design, we did not specifically target participants in the study.

Haynes is concerned that the intervention's effect was at the expense of additional resources. Although some additional resources were required, the intervention was not expensive to run. To enhance generalisability and sustainability we used existing resources whenever possible. Apart from having a full time project officer funded by a grant, the intervention project was encompassed within the other people's usual positions. As the educational materials have been devised, the intervention could be implemented at a similar site with reasonable healthcare resources for the cost of this position.

Deeks and Juszczak's commentary outlines four "deficiencies" that may have affected our findings but seems to conclude that only the lack of a concurrent control group is likely to have introduced bias. We considered these limitations at the outset, but there was no sensible, practical alternative design. Whereas the standard randomised controlled trial design is undeniably valuable, the value should be weighed against the methodological difficulties of health services research.

If undue weight is given to these criticisms our study's important clinical message may be lost. Late life depression is an important public health problem. The effect of intervention was modest but significant. Despite the methodological issues raised, this intervention is a promising way of addressing late life depression in residential care.

\section{Robert H Llewellyn-Jones lecturer} rljones@mail.usyd.edu.au

Karen A Baikie senior research officer

Healthy Aging Research Unit, Hornsby Ku-ring-gai Hospital, Hornsby, New South Wales, 2077,

Australia

1 Llewellyn-Jones RH, Baikie KA, Smithers H, Cohen J, n Jennant CC Multifaceted shared care Snowdon J, Ter late life depression in reside intervention for late life depression in residential care: randomised ci

September

Haynes B. Can it work? Does it work? Is it worth it? BMJ 1999:319:652-653. (18 September)

3 Deeks IJ, Juszczak E. Commentary: Beyond the boundary for a randomised controlled trial? BMJ 1999;319:682. (11 September.)

4 Cameron ID. Recruiting older people for clinical trials and health promotion programs. Med J Aust 1997;167:441.

\section{Design of CRASH trial}

\section{Evidence shows that quality of trial by} Faupel et al is good and therefore should not be excluded

EDITOR-Gregson et al re-analyse the metaanalysis in the systematic review of corticosteroids for acute traumatic brain injury published in the BMJ in 1997, of which I was first author. ${ }^{12}$ They present an argument for excluding from the analysis the trial with the most beneficial results, ${ }^{3}$ thus making the point estimate for the meta-analysis move towards no effect. They use this to condemn the CRASH trial, which is aimed at resolving the uncertainty over the effects of steroids in brain injury.

The systematic review was also published in the Cochrane Library, where it is periodically updated to take account of the results of ongoing searches for studies. ${ }^{4}$ As well as identifying three more small trials presenting data on deaths, we have found more publications reporting the trial by Faupel et al. As detailed in the original 
review, the quality score given to this trial meant that we were unclear about how allocation concealment was ensured (not "poor quality" as suggested by Gregson et al). From one publication ${ }^{5}$ we now have more detail on the procedures used and would classify their use of coded identical vials as adequate quality, or class A. This information will be included in the next update of the review. So there is no reason to exclude this trial on the basis of the quality of allocation concealment as Gregson et al suggest.

Their other argument for ignoring the trial by Faupel et al is that it measured outcomes at discharge, whereas most other trials look at longer term outcomes. We will never know what the outcome of the trial would have been at six months-the apparent benefit of steroids may have decreased, or it could have increased. We judged it better to include the results in the meta-analysis rather than exclude it on the basis of speculation.

Even with their analysis Gregson et al are quite wrong to state that "any possible benefit [of corticosteroids] is eliminated"the confidence interval still includes a clinically important benefit. We are left with continuing uncertainty over the effect of steroids. This cannot be resolved by re-analysis of existing data-only by the addition of more data from large randomised trials.

Phil Alderson associate director

UK Cochrane Centre, Oxford OX2 7LG

palderson@cochrane.co.uk

1 Gregson B, Todd NV, Crawford D, Gerber CJ, Fulton B, Tacconi L, et al. CRASH trial is based on problematic meta-analysis. BMJ 1999;319:578. (28 August)

2 Alderson P, Roberts I. Corticosteroids in acute traumatic brain injury: systematic review of randomised controlled brain injury: systematic review
trials. $B M J$ 1997:314:1855-9.

3 Faupel G, Renlen HJ, Muller D, Schurmann K. Doubleblind study on the effects of steroids on severe closed head injury. In: Pappius MM, Feindel W, eds. Dynamics of brain injury. In: Pappius MM, Feindel W, eds. Dy 4 Alderson P, Roberts I. Corticosteroids for acute traumatic brain injury (Cochrane review). In: The
Issue 3. Oxford: Update Software, 1999.

5 Faupel G. The influence of dexamethasone on the midbrain syndrome after severe head injury. In: Hartmann, Brock M, eds: Treatment of cerebral edema. Berlin Springer Verlag, 1982:107-14.

Trial is best way to elucidate effectiveness of corticosteroids in acute severe head injury

EDITOR-Corticosteroid treatment for acute severe head injury could well reduce the risk of death or severe disability by a few per cent-for example, from $15 \%$ to $13 \%$-and Gregson et al would then be wrong to describe such a benefit as "vanishingly small." The CRASH trial (corticosteroid randomisation after significant head injury) seeks to randomly allocate many thousands of patients to a 48 hour infusion of methylprednisolone or placebo to obtain reliable evidence on whether corticosteroid has a small but real net benefit. ${ }^{2}$ If there is, then hundreds of thousands of future patients could be given this treatment, protecting several thousands from disaster. Moreover, because corticosteroids are routinely given to patients with head injury in many parts of the world, reliable refutation of a benefit could protect thousands of patients from unnecessary corticosteroid administration. ${ }^{3}$ The corticosteroid regimen to be tested in CRASH is similar to that already tested in the NASCIS-2 trial, which showed that such treatment safely produced significant net benefit in acute injury of the spinal cord. ${ }^{4}$

The CRASH protocol references evidence from animal experiments showing possible benefit; it also references the possibility of side effects, the evidence from NASCIS-2 that this treatment regimen helps patients with an acute spinal cord injury, and, of course, the previous such trials in acute head injury. ${ }^{2}$ In doing so, however, it merely claims that, both separately and collectively, those previous trials randomly allocated too few patients to be able to assess a net benefit of "only" a few per cent. The protocol explicitly states that those previous trial results are compatible with the existence of a small net benefit, no net benefit, or even a small hazard, and this remains true whether Gregson et al selectively remove one or a few of those old, small trials.

The uncertainty principle governs entry to the CRASH trial: patients are eligible for randomisation only if the responsible doctor is substantially uncertain about whether they should be offered steroids. ${ }^{5}$ Use of the uncertainty principle simplifies the entry criteria and makes randomisation easier to justify to ethics committees. More importantly, if corticosteroids really can slightly improve the prognosis among patients with significant head injury, then it would be unethical not to get reliable evidence of this The CRASH trial is the best way to seek such evidence.

Ian Roberts CRASH trial clinical coordinator On behalf of the CRASH Trial Management Group, CRASH Coordinating Centre, Institute of Child Health, London WC1N 1EH

Ian.Roberts@ich.ucl.ac.uk

1 Gregson B, Todd NV, Crawford D, Gerber CJ, Fulton B, Tacconi L, et al. CRASH trial is based on problematic Tacconi L, et al. CRASH trial is based on prob
meta-analysis. BMJ 1999;319:578. (28 August.) meta-analysis. BMJ 1999;319:578. (28 August.)
2 CRASH, corticosteroid randomisation after significant 2 CRASH, corticosteroid random

head injury. www.crash.ucl.ac.uk/ 3 Wang Z, Jiang J. Current sta

Trauma Q 1999;14:233-40. 4 Bracken MB, Shepard A randomized, controlled trial of methylprednisolone or naloxone in the treatment of acute spinal-cord injury. Results of the second national acute spinal cord injury study. N Engl J Med 1990;322:1405-11. 5 Peto R, Baigent C. Trials: the next 50 years. $B M$ 1998:317:1170-1.

\section{Routine antenatal HIV testing}

\section{Is justified in areas of low HIV prevalence}

EDITOR-The recent papers by Postma et al and Simpson et al highlight the difficult issues in establishing a policy to test for HIV infection in antenatal clinics. ${ }^{12}$

Postma et al's paper examines the cost effectiveness of universal, voluntary testing of pregnant women in England in terms of healthcare costs to the NHS. Although no cut off point at which the cost for each life year gained becomes acceptable has been defined for England, a cut off point of around $\$ 50000$ is suggested in the United States. They conclude that in areas of high prevalence, such as London, universal, voluntary antenatal screening of pregnant women is cost effective; how- ever, in areas of low prevalence, screening may not be justified in terms of cost effectiveness.

Screening for HIV infection in antenatal clinics fulfils most of Wilson and Junger's criteria as a good test." ${ }^{3}$ HIV infection can be asymptomatic; the tests are simple, relatively pain free, sensitive and specific; and there is effective treatment that can substantially reduce the risk of infection in the fetus. Yet universal testing is not performed in most antenatal clinics. This contrasts with the ad hoc way in which universal screening for Down's syndrome has been introduced in most antenatal clinicsyet none of the individual tests currently available fulfil many of Wilson and Junger's criteria. Tests which are of low risk to the fetus are not very sensitive or specific. In spite of their unproved record, tests are available, sometimes with the patient bearing the cost of testing.

There is stigma surrounding HIV testing; an opt-in policy serves only to reinforce this by testing only those in obvious high risk groups. In low prevalence areas, where there are not large numbers of "high risk" women, those with HIV infection may be even harder to detect from a screening questionnaire as they mingle with the rest of the population. In Portsmouth a third of our HIV positive patients do not fall into any recognised high risk group. Simpson et al's paper shows that for an effective screening programme to be instigated, an opt-out policy of testing is the only model which is effective in antenatal screening; the uptake of the test increased to $88 \%$ compared with a $35 \%$ uptake with an opt-in policy. This policy should be adopted not only for areas of high prevalence of HIV testing but also for areas where the prevalence of HIV infection is low, so that the opportunity to reduce infection in the neonate and treat the asymptomatic mother is not missed.

Elizabeth Foley specialist registrar

V Harindra consultant

Department of Genitourinary Medicine, St Mary's Hospital, Portsmouth PO3 6AD

1 Postma MJ, Beck EJ, Mandalia S, Sherr L, Walters MDS, Houweling $\mathrm{H}$, Jager JC. Universal HIV screening of pregnant women in England: cost effectiveness analysis. $B M J$ 1999;318:1656-60. (19 June.)

2 Simpson WM, Johnstone FD, Goldberg DJ, Gormley SM, Hart GJ. Antenatal HIV testing: assessment of a routine voluntary approach. BMJ 1999;318:1660-1. (19 June.)

3 Wilson JMG, Junger JJ. Principles and practice of screening for disease. Geneva: World Health Organisation, 1968:34.

\section{Is acceptable to women}

Editor-Simpson et al describe a large increase in the uptake of antenatal HIV testing following a change from an opt-in approach to routine testing unless the woman declined. ${ }^{1}$ Their study took place in Edinburgh, and they questioned whether the outcome would be similar in London, 
with its greater cultural and linguistic complexities.

We would like to report our experience of changing the process for antenatal HIV testing in a deprived, multicultural London population with a high prevalence of HIV infection among pregnant women $(0.86 \%$ in 1998; Public Health Laboratory Service, unpublished data). An antenatal HIV testing programme was originally introduced in June 1995; women were offered a test, with signed consent, after discussion with midwives. Despite staff training and support, uptake of testing increased only from 25\% to $33 \%$ by 1998 , and uptake varied widely between individual midwives. ${ }^{2}$

In 1998 HIV testing was integrated into the recommendation of all routine antenatal screening for infection. The new policy was launched on World AIDS Day, 1 December, resulting in supportive local publicity. Currently an updated leaflet giving information about hepatitis B, syphilis, rubella, and HIV infection is sent to women before booking. Discussion and women's decisions about the tests are summarised without a requirement for signed consent. Copies of all negative results are sent to women for inclusion in their handheld notes. Positive results of tests for HIV antibody are given by a consultant obstetrician in conjunction with a health adviser.

The new policy resulted in a rise in uptake in December 1998 to 197/241 (82\%) of women booked through the antenatal clinic. This has been sustained, with an overall uptake of 1440/1605 (90\%) in the first six months for antenatal clinic attendees; community figures are currently being analysed. Antenatal HIV testing identified six infected women between December 1998 and April 1999; all are accepting interventions to minimise vertical transmission.

Women's views were assessed by a questionnaire sent to all women who booked in December 1998. The response rate was 39\%, with $88 \%$ of responders in favour of the HIV test being recommended as a routine blood test in pregnancy. The only negative comments related to the length of time for results to be received by post, and this has since been dealt with.

HIV testing should be a routine part of antenatal care. In our experience this is acceptable to women and results in a dramatic increase in uptake.

Maggie Blott consultant obstetrician Jean Yearwood director of midwifer Marie Gerval clinical research fellow Jan Welch consultant in genitourinary medicine King's College Hospital, London SE5 9RS

Dr Mark Zuckerman consultant virologist Public Health Laboratory Service, Dulwich Hospital, London SE22 8PT

1 Simpson WM, Johnstone FD, Goldberg DJ, Gormley SM, Hart GJ. Antenatal HIV testing: assessment of a routine voluntary approach. BMJ 1999;318:1660-1. (19 June.)

2 Jones S, Sadler T, Low N, Blott M, Welch J. Does uptake of antenatal HIV testing depend on the individual midwife? Cross sectional study. BMJ 1998;316:272-3.

\section{Influence of data display formats on decisions to stop clinical trials}

\section{Paper is misleading, like a sheep dressed in a wolf's clothing}

EDITOR-The abstract of Elting et al's paper gave the impression that icon displays resulted in significantly more correct decisions than did tables $(\mathrm{P}=0.03){ }^{1}$ In fact, the $\mathrm{P}$ value of 0.03 applies only to the comparison between icon displays and bar graphs or pie charts. The $\mathrm{P}$ value for the comparison between icon displays and tables is not significant $(\mathrm{P}=0.17$ ( $\mathrm{p}$ 1529)).

The study showed no significant difference between icon displays and tables for time to make the decision $(\mathrm{P}=0.81)$ or for the quality of the decision. In view of this, the abstract and discussion are deceptive.

James M Walker senior clinical information architect Penn State College of Medicine, PO Box 850 (H-136), Herhey, PA 17033, USA jmwalker@psghs.edu

\section{Elting LS, Martin CG, Cantor SB, Rubenstein EB. Influence of data display formats on physician investiga- tors' decisions to stop clinical trials: prospective trial with repeated measures. BMJ 1999;318:1527-31. (5 June.)}

\section{Authors' reply}

EDITOR-The statement in the abstract regarding the superiority of the icon display is correct, as is the $\mathrm{P}$ value ascribed to the comparison. This reflects the overall comparison among the four displays, using Cochran's $Q$ test of the repeated measures of correct decisions. This is reported in the abstract and the results section because it was the planned analysis of our primary hypothesis. Exploratory, pairwise analyses were also reported. Coincidentally, the $\mathrm{P}$ values for the McNemar tests of the difference between icon displays and the bar charts or pie graphs were also 0.03 ; the $\mathrm{P}$ value for the pairwise comparison between the icon and table displays was 0.17 .

The interpretation of the overall, repeated measures test of the primary hypothesis is straightforward. The accuracy rate with icons was superior to that with the other display methods, and the observed difference was unlikely to have occurred by chance. As is commonly the case with exploratory analyses, however, interpretation of the pairwise comparisons is an exercise in explaining the results of underpowered tests. The study was not powered to test these hypotheses, and the $\mathrm{P}$ value of 0.17 for the difference between the icon displays $(82 \%)$ and table displays $(68 \%)$ reflects the small sample size. (The overall test included 136 observations, and the pairwise tests included only 68 .)

One could argue that a difference of $82 \%$ versus $68 \%$ and a $P$ value $<0.20$ in a small sample warrant further study and that in a larger sample this difference would be significant. As the $\mathrm{P}$ value suggests, however, one could argue equally strongly that there is a $17 \%$ probability that the observed difference occurred by chance alone.
Unfortunately, no matter how one explains the results of underpowered tests, in statistics, as in sheep herding, it's the size of the flock that counts. The prudent reader will cry wolf only in cases justified by adequate sample sizes. Accordingly, we remind readers to interpret the pairwise, exploratory analyses in our study with caution because of their low power. Although underpowered for hypothesis testing, the pairwise comparisons are useful for hypothesis generation. As we have stated, accuracy rates with table displays were intermediate. Future studies should examine this issue.

Linda S Elting associate professor of health services research

Charles G Martin assistant professor of

biomathematics and medicine

Scott B Cantor assistant professor of health services research

Edward B Rubenstein associate professor of medicine Department of Medical Specialties, University of Texas MD Anderson Cancer Center, 1515

Holcombe Boulevard-Box 40, Houston, TX 77030-4095, USA

lelting@notes.mdacc.tmc.edu

\section{Fungal infections of skin and nails of feet}

\section{Pragmatic clinical trial is now needed}

EDITOR-The systematic review on topical treatment for fungal infections of the feet and the accompanying editorial by Finlay illustrate the difficulties encountered when the evidence shows that an alternative treatment is both more effective and more expensive. ${ }^{2}$ Finlay (a member of the advisory board of Novartis, which manufactures the more expensive allylamine treatment) believes that we should give our patients the most effective (and most expensive) treatment. Hart et al provide purchasers with a more balanced view by presenting the costs of treating patients with an azole initially followed by an allylamine against the likely costs of treating all patients with allylamines from the start.

I had always been led to believe that topical terbinafine was vastly superior to azoles in tinea pedis, but the systematic review shows that cure rates were $80 \%$ and $72 \%$ respectively-not a vast difference in absolute terms. So there is at least a case for a policy of "try the cheaper one first and then the more expensive one after" in an NHS that has limited money to spend. Wider debate is needed about whether the inconvenience associated with such a policy for the $8 \%$ of patients who might have been cured if they had been given terbinafine in the first place outweighs the savings. Extrapolated on a national scale, the saving of $£ 155$ per cohort of 100 patients could save around $£ 12.5 \mathrm{~m}$ for the NHS as a whole, even if only a tenth of those with fungal infections of the foot sought medical care-money that arguably could be better spent.

One of the conclusions has to be that a pragmatic clinical trial is now necessary to test the model of azoles first then allylamine 
for treatment failures versus allylamines throughout. Finlay suggests that patients will simply not comply with four weeks' treatment whereas they would with one week's treatment, a hypothesis that is fully testable in a pragmatic trial. Such a trial would also answer the question of whether the $28 \%$ or so of people who do not respond to azoles initially will then respond to the allylamine or whether they represent a subset with resistant fungal species that fail to respond to anything.

Those working for the NHS have a duty not to accept automatically the most effective and expensive treatment but to question the evidence of gains and losses for competing strategies. Far from being confused by the evidence, patients and prescribers are now aware of exactly how much extra benefit they may receive from different treatment choices.

Hywel Williams professor of dermatoepidemiology Centre of Evidence-Based Dermatology, Queen's Medical Centre NHS Trust, University Hospital, Nottingham NG7 2UH

1 Hart R, Bell-Syer EM, Crawford F, Torgerson DJ, Young P, Russell I. Systematic review of topical treatments for fungal infections of the skin and nails of the feet. BMJ infections of the skin

2 Finlay AY. Skin and nail fungi-almost beaten. BMJ 1999;319:71-2. (10 July)

\section{Authors of meta-analysis defend their} view

EDITOR-Finlay's editorial accompanied our systematic review of topical treatments for fungal infections of the skin and nails of the feet. ${ }^{12}$ We agree with the author that it is important to review the evidence for topical treatment in parallel with that for oral treatment. Indeed, our group is currently completing separate systematic reviews of oral treatments for fungal infections of the skin of the feet and for fungal infections of the nails of the feet.

We are concerned that Finlay's main source of evidence for topical allylamines in the treatment of topical dermatophyte infection seems to be a single trial of terbinafine for one week compared with clotrimazole for four weeks. ${ }^{3}$ We excluded this report from our review because the data had already been published. ${ }^{4}$ Furthermore, the results were not entirely consistent with those of another trial with the same first author. This found no significant difference between four weeks of naftifine, another allylamine, and four weeks of clotrimazole and hydrochloride.

To overcome such competing claims from different trials, meta-analysis pools all relevant data. Our estimate of the effectiveness of allylamines relative to azoles summarises the 12 randomised trials that met strict criteria. Aggregated data from 1450 patients show allylamines to be $8 \%$ more effective than azoles ${ }^{2}-$ a smaller difference than that in Finlay's selected trial with only 200 of these patients. ${ }^{3}$

We agree with Finlay that recommendations about treatment in clinical practice should be based on all the relevant available evidence. To our robust evidence about efficacy we therefore added the identifiable costs of prescribing and dispensing the drugs being compared. To fill the gap in evidence about patients' adherence to these drugs, however, further rigorous research is needed in the form of pragmatic (or phase 3) randomised trials. Common sense alone cannot be used to infer how adherence differs between these drugs.

In short, we dispute Finlay's advice that all patients with topical dermatophyte infection should be treated with topical terbinafine. If pharmacists and podiatrists were to follow this advice many patients who could be cured by antifungal cream available over the counter would consult their general practitioners unnecessarily. It is prudent to reserve allylamines for those infections that do not respond to cream available over the counter, at least until good evidence shows that adherence differs substantially between these drugs.

Rachel Hart research podiatrist

Faculty of Community Health Sciences, University of Wales Institute Cardiff, Cardiff CF5 2SG

Sally E M Bell-Syer research fellow

Fay Crawford MRC fellow

PhilipYoung lecturer in biostatistic

Ian Russell professor of health sciences

Department of Health Sciences and Clinical

Evaluation, University of York YO10 5DD

David J Torgerson senior research fellow

Centre for Health Economics, University of York

1 Finlay AY. Skin and nail fungi-almost beaten. $B M$ J 1999;319:71-2. (10 July.)

2 Hart R, Bell-Syer SEM, Crawford F, Torgerson DJ, Young PJ, Russell IT. Systematic review of topical treatments for fungal infections of the skin and nails of the feet. $B M$ 1999:319:79-82. (10 July.)

3 Evans EVG A comparison of terbinafine (Lamisil) 1\% cream given for one week with 1\% clotrimazole (Canestan) given for four weeks in the treatment of tinea pedis. $\mathrm{Br}$ J Dermatol 1994,130:12-4.

lliamon DM, Brown GJ, Bowen Evans EGV, Dodman B, Williamson DM, Brown GJ, Bowen RG. Comparison of terbinafine and clotrimazole in reating tinea pedis. BMJ 1993:307:645-7.

5 Evans EGV, James IGV, Seaman RAJ, Richardson MD. Does naftifine have anti-inflammatory properties? A double blind comparative study with $1 \%$ clotrimazole- $1 \%$ hydrocortisone in clinically diagnosed fungal infection of the skin. BrJ Dermatol 1993;129:437-42.

\section{Teaching medical students about bereavement is hard}

EDITOR-The paper by Saunderson and Ridsdale and the accompanying commentary by Jewell, about attitudes towards responding to bereavement, raise several difficult questions for those teaching undergraduate medical students. ${ }^{1}$ We are told by the doctors interviewed that they were inadequately prepared by their medical school for the task of caring for dying patients. Most medical schools have paid attention to teaching this for some time; it follows that what was taught was inadequate for doctors' needs. It is difficult to know how to teach about the experience of the doctors' grief reaction to the serious illness and death of a patient (guilt, sadness, and anger) without having them experience it.

This takes us to Jewell's suggestion that our own and our medical students' personal experiences are a source of valuable learning and insight. That is true, but harnessing it in a constructive manner may be a problem. I have had the experience of students staying away from a course on care of the dying and bereavement because they believed (wrongly) that I was going to ask them to reveal their own experiences of bereavement to their colleagues. Students come to us with different degrees of acceptance of their losses and abilities to use them as a learning resource. Finding teachers who can deal with these issues sensitively enough may be difficult.

Many medical schools (including my own) have developed courses for students that bring them into contact with patients and potential patients early in their course, at least partly so that they may retain their concept of diversity in the population. Whether we succeed with this aim should be the subject of research in the future.

This is something that is difficult to teach to the full satisfaction of the student; perhaps in the same way that a doctor caring for a dying patient always has a feeling of inadequacy, undergraduate teachers will also have a feeling of inadequacy in how well they have completed their task.

Jon Fuller senior lecturer (jointly responsible for undergraduate teaching)

Department of Primary HealthCare and General

Practice, Imperial College School of Medicine, Chelsea and Westminster Hospital, London SW10 9NP

j.fuller@ic.ac.uk

1 Saunderson EM, Ridsdale L. General practitioners' beliefs and attitudes about how to respond to bereavement: qualitative study [with commentary by $\mathrm{D}$ Jewell]. BMJ 1999;319:293-6. (31 July.)

\section{Cycle helmets}

\section{BMA report does not give the whole picture}

Editor-The Child Accident Prevention Trust was interested to read the report of the BMA's Board of Education and Science on the compulsory use of cycle helmets. ${ }^{1}$ The trust agrees with the board's recommendations, in that society is not yet ready to accept legislation in this area, and the other recommendations on the value of educational efforts to increase the use of cycling in general and of helmet wearing.

However, we would have liked to see more evidence of the effectiveness of helmets in reducing deaths and brain injury, which seems to be important in deciding to what extent helmets should be worn. In the report this is given a somewhat cursory review of just over one page, whereas standards and their verification, and the purchase and care of helmets, receive eight pages. The Child Accident Prevention Trust is the main organisation in Britian concerned solely with the reduction of accidents and injuries to children, but its work in this area and in particular its association with "Headstart" in the sale of low-cost helmets to schoolswhich has so far resulted in the sale of approximately 28000 helmets-is not mentioned at all. 
The report in the $B M J$ is also somewhat unbalanced in that in that it tends to take a negative approach to the problem. ${ }^{2}$ The statement that "a much greater number of lives would be saved if pedestrians and car occupants were encouraged to wear bicycle helmets" is sheer nonsense as it stands, without amplification and qualification.

The Child Accident Prevention Trust is strongly in favour of the promotion of cycling by children and of their use of helmets when doing so, both on the road and in off the road activities.

Hugh Jackson president

Child Accident Prevention Trust, London

EC1R 3AU

safe@capt.demon.co.uk

1 Board of Education and Science. Cycle helmets. London: BMA, 1999.

2 Carnall D. Cycle helmets should not be compulsory. BMJ 1999;318:1505. (5 June.)

\section{Summary of electronic responses}

The BMA's recommendation that cycle helmets should not be compulsory ${ }^{1}$ polarised opinion. ${ }^{2}$ Of the 26 electronic letters, 11 were against compulsory helmet wearing and 10 were in favour.

A Cartmell thinks that car drivers should wear a helmet "since more head injuries occur to car occupants and helmets would be much easier to wear in a car." Others referred to a lack of evidence: "The evidence for the effectiveness of these things is at best inconclusive and the reduction in cycling which would ensue from legislation is a good reason for opposing it" (A Campbell). Wearing a helmet might even increase the problem-by analogy, "Helmet wearing for recreational skiing encourages an increased velocity through added confidence instilled and by identification with ski racing, thus increasing the chance of personal injury and injury to other skiers and reducing any protective benefit of the helmet" (D Sim). This authoritative public health message is substantiated by the observation that "the only danger ... on the road is helmeted speed demons cutting corners and endangering all" (J Rider).

On the other side of the argument, we are reminded that "in 1959 motor manufacturers and safety experts laughed at Volvo for introducing seatbelts. It was thought safer to be thrown clear of a crashing vehicle" (D Carvel). Expressed in personal risks, "all it takes is one event with a head injury to ruin your life" (D Duffield). Compulsory use of cycle helmets seemed to have reduced mortality in New Jersey: "In the year preceding enactment, 14 children died here as the result of cycle injuries. During the first year of implementation, the statewide toll was reduced to only two" (AL Yeager). But "if, as seems likely, deaths fell because the helmet laws dramatically cut the number of children who cycle" (D Carnall) this might not be the right way forward.

Data from Victoria might provide the answer-if we knew what really happened. "Nine years on, however, cycling is more popular in Victoria than it was before" (A Verrinder); or is it because "nine years after mandatory introduction in Australia, cyclist numbers have still not returned to the level pre-legislation-despite a national population increase of well over a million people" (C Gillham)?

1 Carnall D. Cycle helmets should not be compulsory. BMJ 1999;318:1505. (5 June.)

2 Electronic responses. Cycle helmets should not be compulsory. $e B M J$ 1999;318 www.bmj.com/coi/content/ full/318/7197/1505/a\#responses (accessed 27 July 1999).

\section{The coroner service}

\section{Coroner service could indeed be improved}

EDITOR-I recognise the need for society and the judiciary to be able to check up on medical practitioners, but I strongly concur with Pounder's views that the coroner service could be improved. ${ }^{1}$ A 49 year old patient of the practice where I work died peacefully at home recently of cerebral metastases from lung cancer. He had been ably cared for by his wife and daughters with help from the district and hospice nurses in liaison with one of my partners and our local oncologist. I attended to confirm death, but as he had not needed to see a doctor in the last month or so the coroner would not permit me to issue the death certificate. After some negotiation and despite being sympathetic, he did consent to my partner issuing the death certificate on her return from holiday four days later, although he would not have done so had she not been due back so soon.

There seemed no doubt about our patient's identity or place or cause of death, and there certainly was no hint of foul play.

This case is by no means an isolated one, and I am sure that many of my general practitioner colleagues are tempted to overlook the rules in straightforward natural deaths to protect relatives from interference. I believe that the public would welcome the opportunity to express their views and am equally sure that they would support modernisation of this archaic but important service.

James Pilpel general practitioner

The Surgery, Tean, Stoke on Trent ST10 4EG

1 Pounder D. The coroner service. BMJ 1999;318:1502-3. (5 June.)

\section{Inquests often facilitate grief}

EDITOR-Pounder's editorial on the coroner service fails to raise important issues in relation to bereavement and the existing coroner service. ${ }^{1}$ There is a conflict of interest between the "enforceable intrusion" of a coroner's inquest to ascertain the cause of a sudden death and the needs of relatives.

A previous editorial in the $B M J$ stated that an inquest is conducted at a "time of greatest grief, distress, and uncertainty,"' and yet general practitioners do not routinely receive necropsy reports from the coroner and so are not in an informed position to tell relatives how the person died. Furthermore, doctors may be inhibited by the standard admonition regarding a coroner's report that the content should not be disclosed to a third party without consent. ${ }^{3}$

Pounder correctly questions why so many inquests are conducted. But inquests provide relatives with an opportunity to understand the cause of death, which may aid in the grieving process after this traumatic and intimate examination. Indeed, this information may assist in confirming the inevitability of death and help to dispel feelings of doubt, guilt, and anger.

Rodger Charlton general practitioner principal The Surgery, Hampton-in-Arden, Solihull B92 0AH charlton@monfode.demon.co.uk

1 Pounder D. The coroner service. BMJ 1999:318:1502-3. (5 June.)

2 Turner J, Raphael B. Requesting necropsies. BMJ 1997;314:1499-500.

3 Karunaratne S, Benbow EW. A survey of general practitioners' views on autopsy reports. J Clin Pathol 1997;50:548-52.

4 Start RD, Saul CA, Cotton DWK, Mathers NJ, Underwood JCE. Public perceptions of necropsy. J Clin Pathol $1995 ; 48: 497-500$

\section{All sudden infant deaths must be investigated thoroughly}

EDITOR-Pounder states that the coroner service should focus "more narrowly on deaths of legitimate medicolegal interest" and implies that a reduction in referrals and necropsies could "reflect a greater sensitivity to the rights of the next of kin."1 I am concerned that such a move might reduce the coroner's role in sudden and unexpected infant deaths, resulting in poorer detection of cases of child abuse or neglect. This is highlighted by a development in Australia, where the coroner's right to necropsy has been overturned in its High Court by parents on religious or ethical grounds.

Cases of sudden and unexpected infant death in the United Kingdom are referred to the coroner for investigation, and the police are responsible for determining whether deaths are natural or arise from child abuse or neglect. Deaths arising from child abuse or neglect are difficult to detect, even when minor, but non-lethal, injuries are found at necropsy. ${ }^{3}$

There are now reports of cases of infant death that have been presumed to be natural (sudden infant death syndrome) but on subsequent presentation of a sibling with child abuse were found to have been due to infanticide only after further investigations by several agencies. ${ }^{4}$ It is accepted that a postmortem examination alone may not be able to identify intentional suffocation as a mechanism unless there are other injuries. Thus a postmortem examination cannot differentiate between intentional suffocation and sudden infant death syndrome (a diagnosis of exclusion).

I suggest that multiagency investigations by child death review teams should become mandatory to help distinguish deaths resulting from abuse or neglect from those due to natural mechanisms. ${ }^{5}$ The coroner should initiate such reviews to ensure that deaths due to abuse are not missed and that living siblings may be adequately protected from the abuse that can be meted out by parents 
who kill their children in this way. Recent data show that a proportion of sudden infant deaths result primarily from abuse or neglect (figures of $10 \%$ quoted $^{5}$ ). It is therefore in the interests of living and dead children, as well as innocent parents who have suffered a natural tragedy, for the recommendations of the Confidential Enquiries into Stillbirths and Deaths in Infancy to be implemented by statute.

Martin Samuels senior lecturer in paediatrics Academic Department of Paediatrics, North Staffordshire Hospital, Stoke on Trent ST4 6QG doctorsamuels@hotmail.com

Pounder D. The coroner service. BMJ 1999;318:1502-3 (5 June.)

2 Green $v$ Graeme Douglas Johnstone State Coroner. Ref 1995 No 4574.

3 Green MA. A practical approach to suspicious death in infancy - a personal view. J Clin Pathol 1998;51:561-3.

4 Southall DP, Plunkett MCB, Banks MW, Falkov AF Samuels MP. Covert video recordings of life-threatening child abuse: lessons for child protection Pediatrics 1997;100:735-60.

5 Confidential Enquiry into Stillbirths and Deaths in Infancy 3rd Anmul report: sudden umexpected death in infancy. 3rd An al Dert. sudden unexpected deaths in of Health, 1996

\section{Culturally sensitive care for the dying is} basic human right

EDITOR-In many traditions the concept of "a good end" has reality and significance. This is particularly true for Muslims. Much time and energy will be invested by family and friends to help ensure that the dying end the earthly phase of their existence in a state of peace in both their internal and their external worlds. Internally, this involves inculcating in the dying a sense of hope and optimism in Allah's forgiveness, mercy, and reward. Externally, this involves setting matters right with one's relatives and friends while the opportunity still exists. Those who are fortunate enough to die in such a state are, within the Muslim paradigm, successful. On death there is a communal responsibility to lay the dead person to rest swiftly and with dignity.

The hope for a good end is the silent lifelong prayer of many people, yet in the course of our daily work we are reminded that achieving this basic human right is often difficult for British Muslims. We welcome Pounder's editorial, ${ }^{1}$ recognising how deeply disturbing a coroner's investigation and the necropsy that often follows can be for those from certain religious traditions.

We would agree that the coroner's service is "a relic in need of reform," but it is just one of many issues that need to be tackled if we are to deliver culturally competent care to the dying and their families. Hospital visiting restrictions should be more flexible, the rule of two visitors per bed being inappropriate for dying patients from cultures in which visiting such people is regarded as a religious obligation. In addition, appropriate hospital prayer facilities should be available for patients and their relatives and visitors.

The importance of a prompt burial for Jews and Muslims must be recognised, and systems put in place to facilitate this practice, such as the ability to register and bury one's dead at weekends and on public holidays.
Perhaps the single most important change that will result in culturally sensitive care is a greater emphasis on transcultural medicine in the medical curriculum; tomorrow's clinicians and health policymakers would then have the opportunity to understand the range of needs of dying patients found in modern day pluralist Britain.

Aziz Sheikh clinical research fellow Imperial College School of Medicine, London W2 $1 \mathrm{PG}$

aziz.sheikh@ic.ac.uk

A R Gatrad consultant paediatrician

Manor Hospital, Walsall WS2 9PS

Sangeeta Dhami locum general practitioner GP Direct, West Harrow, Middlesex HA5 4EA

1 Pounder D. The coroner service. BMJ 1999;318:1502-3. (5 June.)

2 Spitzer J.A guide to the orthodox Jewish way of life for healthcar professionals. 2nd ed. London: Spitzer, 1998.

\section{A national service would be more} consistent

EdTOR-In his editorial Pounder suggests that the coroner's service could be vastly improved by having a national system in place rather than the local services that currently exist. ${ }^{1}$ Our work on the Confidential Enquiry into Stillbirths and Deaths in Infancy incorporates two health regions, and we rely on the coroners to provide us with information about fetal and infant deaths. We have found many local variations.

One difference is that in some districts a specialist perinatal pathologist performs the necropsies on babies while in others this is not the case. Such specialist reports provide valuable and sometimes previously unknown information on the cause of death and can help in the management of the future pregnancies of the parents of children who have died. ${ }^{2-4}$ The Royal College of Pathologists strongly recommends that necropsies on infants should be carried out by a specialist pathologist, ${ }^{5}$ and we at the Confidential Enquiry into Stillbirths and Deaths in Infancy agree with this. This is true of all cases, including (and perhaps especially) those reported to the coroner.

We have always found the coroners and their staff to be extremely helpful and supportive of our work. We agree with Pounder, though, that a national system would be far more beneficial and consistent, both for the families of the infants who have died and for data collection purposes.

Judith Levitan information manager, CESDI North Thames West

nwthames@cesdi.org.uk

Brenda K Dines database manager, CESDI North Thames East

North Thames Perinatal Public Health, Northwick Park Hospital, Harrow, Middlesex HA1 3UJ

1 Pounder D. The coroner service. BMJ 1999;318:1502-3 (5 June.)

2 Thornton CM, O'Hara MD. A regional audit of perinatal and infant autopsies in Northern Ireland. $\mathrm{Br} J$ Obstet Gynaecol 1998; 105:18-23.

3 Stambouly JJ, Kahn E, Boxer RA. Correlation between clinical diagnoses and autopsy findings in critically ill children. Pediatrics 1993;92:248-51.

4 Rushton DI. Prognostic role of the perinatal postmortem BrJ Hosp Med 1994:52:450-4.

5 Confidential Enquiry into Stillbirths and Deaths in Infancy 5th Anmul report: maternal and child health. London: Maternal and Child Health Research Consortium, 1998 .

\section{Attribution of time lag theory to explain French paradox}

EDITOR-After the publication of our paper in the $B M J$ of 29 May on why mortality from heart disease is low in France (the French paradox), ${ }^{1}$ it was drawn to our attention that the time lag explanation that we set out in our paper had previously been put forward, by Marion Nestle, in a letter to the Lancet in 1992. ${ }^{2}$ We were not aware of this attribution, and we would have cited it if we had been.

Malcolm Law reader

Nicholas Wald professor

Wolfson Institute of Preventive Medicine,

St Bartholomew's and the Royal London School of

Medicine and Dentistry, London EC1M 6BQ

1 Law M, Wald N. Why heart disease mortality is low in
France: the time lag explanation. BMJ 1999;318:1471-80.
(29 May.)
2 Nestle M. Wine and coronary heart disease. Lancet 1992;40:314-5.

\section{Pens are certainly more portable than computers}

EDITOR-My normal handwriting is so bad that a physician friend has deservedly commented, "Your only attribute for being a physician is your handwriting." Yet this friend's writing is admirably clear.

A while back, on reading a note that I had written to myself, I found that not only could I not decipher it but I had no idea what it was about, even from the context. So it was a matter of either learning touch typing or improving my handwriting; certainly handwriting seemed more versatile. I did some reading and found that the humanist script (used by monks for fast writing) was legible; the modern descendant is italic script.

I took an evening class in calligraphy and soon found myself rapped over the knuckles by the teacher, for "calligraphy is an art form and not to be used for everyday writing." Anyway, I use italic for all correspondence except electronic mail, take a photocopy, and have found that people seem to prefer the personal touch. A pen weighs much less than a laptop and printer for trips.

Apparently there has been a resurgence of ink pens among undergraduates in the United States. I have surveyed people at recent physics conferences: it's obvious that the great majority in this computer-happy trade use pens and paper and pocket paper diaries. Perhaps correspondents could tell me of good italic ink pens now that my favourite is being discontinued.

Len Finegold physicist

Drexel University, Philadelphia, PA 19104, USA

L@Drexel.edu

1 Dunea G. Beastly handwriting. BMJ 1999;319:65. (3 July.)

Rapid responses
Correspondence submitted electronically
is available on our website www.bmj.com

